features and ethical issues in RICU) [3, 11]; fellowships; and the Junior Members Committee within the Long Range Planning Committee.

In conclusion, the findings of our survey depict the characteristics of the Noninvasive Ventilatory Support Group members as a heterogeneous pool of subjects, showing a different degree of expertise with a predominance of pulmonologists who manage patients in low-intensity settings with both acute and chronic respiratory failure. Current and future activities of the Group and its Assembly are directed to increase the awareness of all ERS members to the central role covered by NIV in respiratory medicine and to coherently improve the skills of old and new members.

@ERSpublications

Survey showing ERS NIV group is heterogeneous with different degree of expertise and predominance of pulmonologists http://ow.ly/tAa0D

Raffaele Scala ${ }^{1}$, Wolfram Windisch ${ }^{2}$, Thomas Köhnlein ${ }^{3}$, Antoine Cuvelier ${ }^{4,5}$, Paolo Navalesi ${ }^{6,7,8}$ and Paolo Pelosi ${ }^{9}$ on behalf of European Respiratory Society Respiratory Intensive Care Assembly

${ }^{1}$ Pulmonology Unit and Respiratory Intensive Care Unit, S. Donato Hospital, Arezzo, Italy. ${ }^{2}$ Dept of Pneumology, Cologne-Merheim Hospital, Cologne, Germany. ${ }^{3}$ Dept of Respiratory Medicine, Hannover Medical School, Hannover, Germany. ${ }^{4}$ Pulmonary and Intensive Care Dept, Rouen University Hospital, Rouen, France. ${ }^{5}$ UPRES EA 3830 (IFR MP23), Institute for Biomedical Research, Rouen, France. ${ }^{6}$ Dept of Translational Medicine, Università del Piemonte Orientale "Amedeo Avogadro", Novara, Italy. ${ }^{7}$ Anaesthesia and Intensive Care Medicine, Sant'Andrea Hospital (ASL VC), Vercelli, Italy. ${ }^{8}$ CRRF Mons. L. Novarese, Moncrivello, Italy. ${ }^{9}$ Dept of Surgical Sciences and Integrated Diagnostics, University of Genoa, Genoa, Italy.

Correspondence: Raffaele Scala, Pulmonology Unit and Respiratory Intensive Care Unit, S. Donato Hospital, Via P. Nenni, 20, Arezzo, Italy. E-mail: raffaele_scala@hotmail.com

Received: Sept 212013 | Accepted after revision: Oct 092013

Conflict of interest: Disclosures can be found alongside the online version of this article at err.ersjournals.com

Provenance: Submitted article, peer reviewed.

\title{
References
}

European Respiratory Society. Who we are. www.ersnet.org/about-us/who-we-are.html Date last accessed: September 1, 2013.

Nava S, Hill N. Non-invasive ventilation in acute respiratory failure. Lancet 2009; 374: 250-259.

Corrado A, Roussos C, Ambrosino N, et al. Respiratory intermediate care units: a European survey. Eur Respir J 2002; 20: 1343-1350.

Hill NS. Where should noninvasive ventilation be delivered? Respir Care 2009; 54: 62-70.

Ozsancak A, D’Ambrosio C, Hill NS. Nocturnal noninvasive ventilation. Chest 2008; 133: 1275-1286.

Nava S, Navalesi P, Conti G. Time of non-invasive ventilation. Intensive Care Med 2006; 32: 361-370.

Ambrosino N, Guarracino F. Unusual applications of noninvasive ventilation. Eur Respir J 2011; 38: 440-449.

Nava S, Evangelisti I, Rampulla C, et al. Human and financial costs of noninvasive mechanical ventilation in patients affected by COPD and acute respiratory failure. Chest 1997; 111: 1631-1638.

9 Carlucci A, Delmastro M, Rubini F, et al. Changes in the practice of non-invasive ventilation in treating COPD patients over 8 years. Intensive Care Med 2003; 29: 419-425.

10 Artigas A, Pelosi P, Dellweg D, et al. Respiratory critical care HERMES syllabus: defining competencies for respiratory doctors. Eur Respir J 2012; 39: 1294-1297.

11 Nava S, Sturani C, Hartl S, et al. End-of-life decision-making in respiratory intermediate care units: a European survey. Eur Respir J 2007; 30: 156-164.

\section{Chronic thromboembolic pulmonary hypertension complicating long-term cyproterone acetate therapy}

To the Editor:

Chronic thromboembolic pulmonary hypertension (CTEPH) is the most severe delayed complication after pulmonary embolism. Known risk factors of CTEPH include acute pulmonary embolism, the degree of 

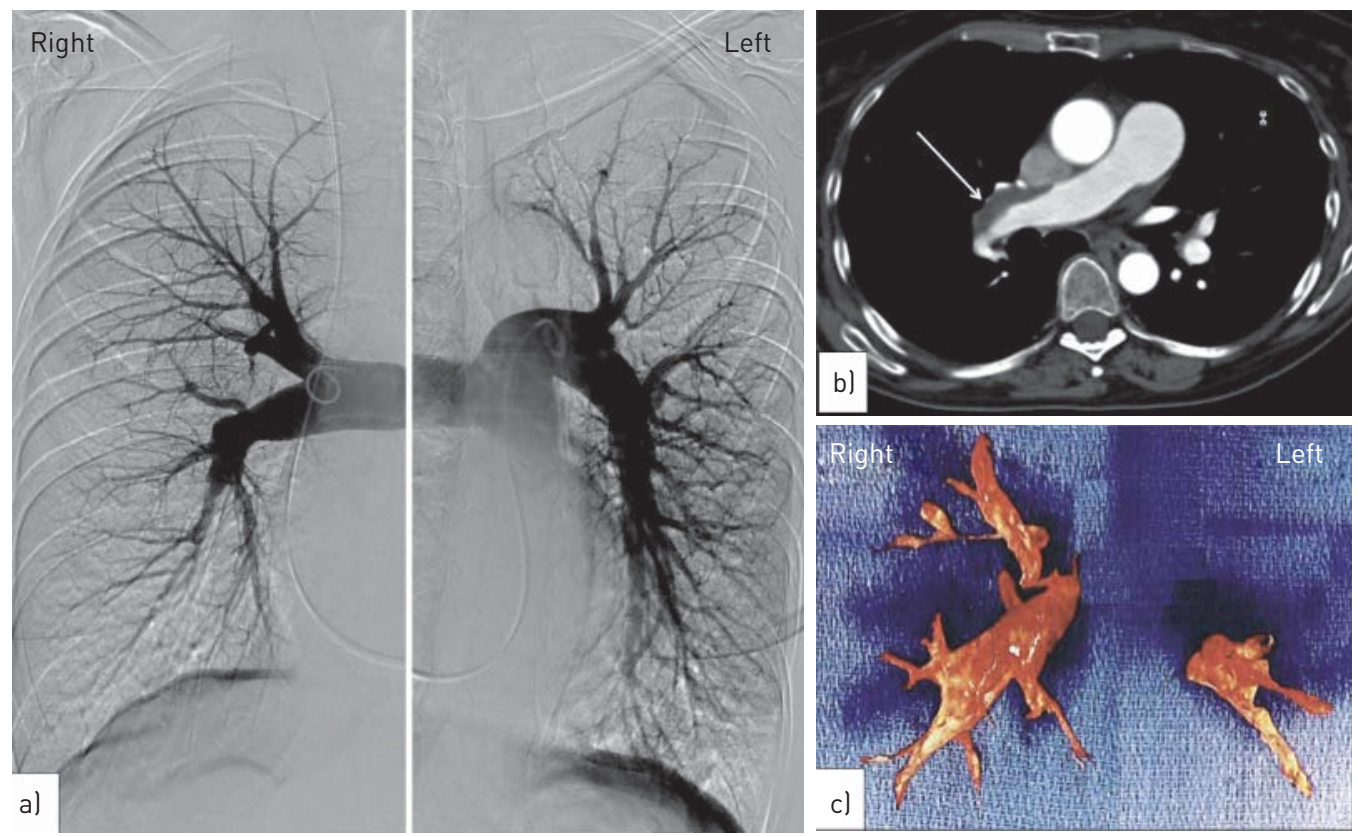

FIGURE 1 a) Selective pulmonary angiogram of the right and left main pulmonary arteries confirmed the diagnosis of chronic thromboembolic pulmonary hypertension with bilateral proximal obstruction of the pulmonary arteries. b) Computed tomography of the chest showing organised thromboembolic material in the main right pulmonary artery (arrow). c) Organised thromboembolic material removed during pulmonary endarterectomy.

pulmonary arterial occlusion, pulmonary embolism recurrence, splenectomy, ventriculo-arterial shunts, infected pacemakers and blood group $\mathrm{O}[1,2]$. Symptomatic pulmonary embolism is found in almost three-quarters of patients with CTEPH [3]. Cyproterone acetate, a synthetic steroidal antiandrogen drug with additional progestogen and antigonadotropic properties, is a major risk factor of venous thromboembolic disease $[4,5]$. We report the first case of severe CTEPH occurring in the context of cyproterone acetate long-term exposure.

A 55-year-old female was referred to our centre (French referral centre for pulmonary hypertension) for pulmonary hypertension. She was a former smoker (30 pack-years) and her medical history included migraine, systemic hypertension and severe acne (treated with cyproterone acetate, $50 \mathrm{mg}$ daily) between 1992 and 2010 associated with ethinylestradiol therapy. The patient had no past history of pulmonary embolism or deep vein thrombosis. No risk factors for CTEPH other than cyproterone acetate exposure were identified. In 2010, the patient reported exertional dyspnoea and cyproterone acetate was stopped. The patient experienced progressive dyspnoea during the following 18 months, and the patient was in New York Heart Association (NYHA) functional class III at the time of the first evaluation. Pulmonary hypertension was suspected on Doppler echocardiography and right heart catheterisation confirmed severe pre-capillary pulmonary hypertension with a mean pulmonary arterial pressure of $52 \mathrm{mmHg}$, a normal pulmonary artery wedge pressure, a low cardiac index of $1.76 \mathrm{~L} \cdot \mathrm{min}^{-1} \cdot \mathrm{m}^{-2}$, an increased total pulmonary resistance of 19.6 Wood Units (WU), and a low mixed venous oxygen saturation of 51\%. Her 6-min walk distance was $265 \mathrm{~m}$. A ventilation/perfusion lung scan showed multiple bilateral perfusion defects with normal ventilation. Helical computed tomography of the chest and pulmonary angiogram (fig. 1a and b) confirmed the diagnosis of CTEPH with bilateral proximal obstruction of the pulmonary arteries. Pulmonary endarterectomy was successfully performed allowing removal of organised material (fig. 1c). Evolution was favourable with a decrease of total pulmonary resistance to $6 \mathrm{WU}$ immediately after surgery. 2 years after surgery the patient showed persistent clinical benefit (NYHA functional class I).

We report the first case of CTEPH potentially associated with long-term exposure to cyproterone acetate. This antiandrogen therapy, widely used in the field of oncology for the treatment of prostatic neoplasia (100-300 $\left.\mathrm{mg} \cdot \mathrm{day}^{-1}\right)$, is a major risk factor of pulmonary embolism in males with prostatic neoplasia [6]. Lower doses of cyproterone acetate $\left(2-100 \mathrm{mg} \cdot \mathrm{day}^{-1}\right)$ are commonly used outside the oncological setting, and cyproterone acetate has been proposed for the management of severe acne and hirsutism, reduction of sexual pulsion and as a method of birth control, in addition to ethinylestradiol [7]. Even at these lower doses $\left(2 \mathrm{mg} \cdot \mathrm{day}^{-1}\right)$, cyproterone acetate is still associated with high risks of venous thromboembolic disease 
(seven-fold increased risk) [4, 7]. It is worth noting that, this risk increases with the duration of exposure and with the patient's age [4]. Due to this, the Pharmacovigilance Risk Assessment Committee of the European Medicines Agency (EMEA) recently reviewed the risk/benefit ratio of this drug, particularly the association of cyproterone acetate $(2 \mathrm{mg}) /$ ethinylestradiol $(35 \mu \mathrm{g})$, which is widely used across Europe for the treatment of acne or as oral contraception. The EMEA maintained that these drugs could be used in the treatment of moderate-to-severe acne related to androgen sensitivity and/or hirsutism in females of reproductive age, but only after topical therapy or systemic antibiotic treatments failed [8]. Due to the fact that these drugs act as hormonal contraceptives, they cannot be used in combination with other hormonal contraceptives [8]. Notably, hormonal therapy is not recognised as a usual risk factor for CTEPH [2, 3, 9]. However, the present case indicates that long-term exposure to a high dose of cyproterone acetate may be a risk factor for CTEPH. As previously emphasised in pulmonary arterial hypertension [10-12], complete information on drug exposure should be systematic in patients presenting with CTEPH in order to identify as yet unrecognised possible drug-induced cases. Several drugs have been recognised recently as being associated with an increased risk of pulmonary arterial hypertension, e.g. dasatinib in patients with chronic myelogenous leukaemia. Beside its role in thrombosis, cyproterone acetate should also be recognised as an increased risk factor of CTEPH. Thus, clinicians should also consider chronic venous thromboembolism as CTEPH in patients exposed to cyproterone acetate.

0 @ERSpublications

Long-term exposure to cyproterone acetate may be a risk factor for chronic thromboembolic pulmonary hypertension http://ow.ly/tAoGo

David Montani ${ }^{1,2,3}$, Laurent Bertoletti ${ }^{4,5}$, Marie-Camille Chaumais ${ }^{3,6,7}$, Swanny Perrin ${ }^{1,2,3}$, Dominique Fabre ${ }^{3,8}$, Ari Chaouat $^{9}$, Xavier Jaiis ${ }^{1,2,3}$, Gérald Simonneau ${ }^{1,2,3}$ and Marc Humbert ${ }^{1,2,3}$

${ }^{1}$ Université Paris-Sud, Faculté de Médecine, Kremlin-Bicêtre, France. ${ }^{2}$ AP-HP, Centre de Référence de l'Hypertension Pulmonaire Sévère, Département Hospitalo-Universitaire (DHU) Thorax Innovation, Service de Pneumologie et Réanimation Respiratoire, Hôpital de Bicêtre, Le Kremlin-Bicêtre, France. ${ }^{3}$ UMR-S 999, INSERM and Université ParisSud, Laboratoire d'Excellence (LabEx) en Recherche sur le Médicament et l'Innovation Thérapeutique (LERMIT), Centre Chirurgical Marie Lannelongue, Le Plessis Robinson, France. ${ }^{4} \mathrm{CHU}$ de St-Etienne, Service de Médecine et Thérapeutique, Hopital Nord, St-Etienne, France. ${ }^{5}$ Université Jean-Monnet, Groupe de Recherche sur la Thrombose (EA 3065), StEtienne, France. ${ }^{6}$ Université Paris-Sud, Faculté de Pharmacie, Chatenay-Malabry, France. ${ }^{7}$ AP-HP, Département Hospitalo-Universitaire (DHU) Thorax Innovation, Service de Pharmacie, Hôpital Antoine Béclère, Clamart, France. ${ }^{8}$ Centre Chirurgical Marie Lannelongue, Le Plessis Robinson, France. ${ }^{9} \mathrm{CHU}$ Hôpital de Brabois, Service des Maladies Respiratoires et Réanimation Respiratoire, Vandoeuvre-lès-Nancy, France.

Correspondence: D. Montani, AP-HP, Centre de Référence de l'Hypertension Pulmonaire Sévère, Service de Pneumologie et Réanimation Respiratoire, DHU Thorax Innovation, Hôpital de Bicêtre, 78 rue du Général Leclerc, 94270 Le KremlinBicêtre, France. E-mail: david.montani@bct.aphp.fr

Received: Aug 282013 | Accepted after revision: Sept 182013

Support statement: The French Pulmonary Hypertension Pharmacovigilance Network (VIGIAPATH) is supported by the Agence Nationale de Sécurité du Médicament et des Produits de Santé (ANSM).

Conflict of interest: Disclosures can be found alongside the online version of this article at err.ersjournals.com

Provenance: Submitted article, peer reviewed

\section{References}

1 Lang IM, Pesavento R, Bonderman D, et al. Risk factors and basic mechanisms of chronic thromboembolic pulmonary hypertension: a current understanding. Eur Respir J 2013; 41: 462-468.

2 Bonderman D, Wilkens $\mathrm{H}$, Wakounig S, et al. Risk factors for chronic thromboembolic pulmonary hypertension. Eur Respir J 2009; 33: 325-331.

3 Pepke-Zaba J, Delcroix M, Lang I, et al. Chronic thromboembolic pulmonary hypertension (CTEPH): results from an international prospective registry. Circulation 2011; 124: 1973-1981.

4 Van Hylckama Vlieg A, Helmerhorst FM, Vandenbroucke JP, et al. The venous thrombotic risk of oral contraceptives, effects of oestrogen dose and progestogen type: results of the MEGA case-control study. BMJ 2009; 339: b2921.

5 Van Hylckama Vlieg A, Middeldorp S. Hormone therapies and venous thromboembolism: where are we now? J Thromb Haemost 2011; 9: 257-266.

6 Van Hemelrijck M, Adolfsson J, Garmo H, et al. Risk of thromboembolic diseases in men with prostate cancer: results from the population-based PCBaSe Sweden. Lancet Oncol 2010; 11: 450-458.

7 Lidegaard O, Nielsen LH, Skovlund CW, et al. Risk of venous thromboembolism from use of oral contraceptives containing different progestogens and oestrogen doses: Danish cohort study, 2001-9. BMJ 2011; 343 : d6423.

8 European Medicines Agency. Benefits of Diane 35 and its generics outweigh risks in certain patient groups. www.ema. europa.eu/ema/index.jsp?curl=pages/medicines/human/referrals/Cyproterone-_and_ethinylestradiol-containing medicines/human_referral_prac_000017.jsp\&mid=WC0b01ac05805c516f Date last updated: August 5, 2013. Date last accessed: February 26, 2014. 
10 Montani D, Bergot E, Günther S, et al. Pulmonary arterial hypertension in patients treated by dasatinib. Circulation 2012; 125: 2128-2137.

11 Savale L, Chaumais MC, Cottin V, et al. Pulmonary hypertension associated with benfluorex exposure. Eur Respir J 2012; 40: 1164-1172.

12 Souza R, Humbert M, Sztrymf B, et al. Pulmonary arterial hypertension associated with fenfluramine exposure: report of 109 cases. Eur Respir J 2008; 31: 343-348.

\title{
The thoracic cage becomes flattened in the progression of pleuroparenchymal fibroelastosis
}

\author{
To the Editor:
}

Pleuroparenchymal fibroelastosis (PPFE) was first reported by FRANKEL et al. [1]. PPFE can occur without any aetiology or underlying diseases (idiopathic PPFE), or with underlying diseases or conditions. Idiopathic PPFE has been listed as one of the rare idiopathic interstitial pneumonias (IIPs) in the revised international multidisciplinary consensus classification of IIPs [2]. The natural history of PPFE is variable, some are slowly progressive and others sometimes show rapid deterioration resulting in poor prognosis, like idiopathic pulmonary fibrosis (IPF). Idiopathic pulmonary upper lobe fibrosis (PULF), first proposed by AMITANi et al. [3], is currently considered to be almost identical to idiopathic PPFE [1, 4, 5], which is now globally accepted as a representative nomenclature for this disorder. Therefore, we use the term PPFE to describe the same disease as PULF.

AMITANi et al. [3] recognised a characteristic constitution in patients with PPFE: they are slender and their thoracic cage is flattened, i.e. the ratio of the anteroposterior diameter of the thoracic cage (APDT) to the transverse diameter of the thoracic cage (TDT) is abnormally lower than in normal populations. Herein, we have provisionally named this deformity of the thoracic cage as "flat chest". Other investigators have also noticed this deformity in idiopathic PPFE [6-8]. Flat chest may result from a congenital disposition or may be an acquired deformity of the thoracic cage associated with fibrosing upper lung lobes.

We assessed the APDT/TDT ratio in patients with PPFE. Subsequently, we examined whether flat chest became more pronounced during the progression of the disease. Based on clinical files from our hospitals, eight patients with PPFE in whom the APDT/TDT ratio had been measured twice with an interval of $\geqslant 1.87$ years using chest computed tomography (CT) were retrospectively enrolled. TDT was determined as the longest transverse diameter of the thoracic cage measured parallel to a line (line \#) along the rearmost points of the 6th thoracic vertebra in the horizontal section of the chest CT (fig. 1a). APDT was determined as the longest distance of the anteroposterior dimension of the thoracic cage measured perpendicular to the line along the rearmost points of the 6th thoracic vertebra (line \#). In addition, TDT and APDT were also defined as the distances from the inside of a rib to the inside of the opposite rib. If APDT in one hemithorax was different to the APDT in the other hemithorax, a mean value was adopted. We also compared the change in forced vital capacity (FVC) during the interval between the two measurements of APDT/TDT. The first FVC was defined as the FVC measured around the first measurement of APDT/TDT, with a time lag $<4 \%$ of the interval between the two measurements of APDT/TDT. The second FVC was defined as the FVC measured around the second APDT/TDT, with intervals of 1.42-4.67 years between the two measurements of FVC.

In case 2, flat chest became more pronounced after an interval of 5.27 years: APDT/TDT decreased from 0.592 to 0.509 and FVC decreased from 3540 to $1120 \mathrm{~mL}$ (fig. 1). In eight patients, the APDT/TDT became significantly lower after intervals of 1.87 to 5.27 years (paired t-test, $p=0.003$ ), during which FVC was remarkably decreased in six patients (table 1 ).

Barrel chest is a well-known acquired deformity of the thoracic cage in patients with advanced pulmonary emphysema. It is possible that a long-standing increase in intrathoracic pressure, caused by overinflated lungs associated with obstructive ventilatory impairment, leads to an expansion of the thoracic cage into 